\title{
Evaluation of semi-hybrid perennial ryegrass populations
}

\author{
B.A. BARRETT ${ }^{1}$, M.A. TURNER ${ }^{1}$, T.B. LYONS ${ }^{1}$, M.P. ROLSTON ${ }^{2}$ and H.S. EASTON ${ }^{1}$ \\ ${ }^{1}$ AgResearch, Grasslands Research Centre, Private Bag 11008, Palmerston North \\ ${ }^{2}$ AgResearch, Lincoln Research Centre, PO Box 60, Lincoln
}

brent.barrett@agresearch.co.nz

\begin{abstract}
The yield potential of modern forage cultivars is a limit to production from pasture- based agriculture, and may influence profitability. Hybrid vigour has increased yield in a range of plant species, but is only partially captured in conventional forage breeding systems. The objective of this research was to assess the potential for harnessing hybrid vigour in a semi-hybrid breeding system for perennial ryegrass (Lolium perenne). Paired crosses among eight parental sources, including four cultivars and four ecotypes, were used to create 28 semi-hybrid populations. Parents, semi-hybrids and check cultivars were trialled in pure grass plots under rotational grazing for 2 years in the Manawatu. Dry matter yield data were used to estimate cumulative and seasonal patterns of hybrid vigour expression for cultivar $\mathrm{x}$ cultivar semi-hybrid combinations. The mean level of high parent heterosis was less than $2 \%$. However, one combination exhibited significant $(\mathrm{P}<0.05)$ high parent heterosis of $7 \%$ for cumulative yield. Seasonal levels of heterosis expression ranged up to $11 \%$ in winter and $19 \%$ in spring, with lower expression in the summer and autumn. These data suggest hybrid vigour may be expressed in some combinations among current populations, and that further experiments to identify superior combinations are warranted. Adoption of a semi-hybrid breeding system for variety development would have implications for population improvement, seed production and certification, and plant variety rights.
\end{abstract}

Keywords: Lolium, heterosis, hybrid, yield

\section{Introduction}

Pasture dry matter (DM) yield on grazing-based farms is a limit to production and may influence profitability. Plant breeders have achieved substantial yield gains in cereals and other crops (Baenziger et al. 2006). Gains have also been made in perennial forage species (Woodfield \& Caradus 1994; Woodfield \& Easton 2004).

Perennial ryegrass (Lolium perenne) comprises the majority of the ruminant diet in New Zealand. The species has marked seasonal fluctuations in DM yield, which limits carrying capacity on some farms. Since the introduction of early cultivars to New Zealand farms, plant breeding has achieved genetic gain for DM yield in perennial ryegrass as estimated in small plot trials (Easton et al. 2001; Williams et al. 2007).

The relatively low rate of genetic gain for yield in perennial ryegrass is attributed to several constraints including the genetic basis of traits under selection, the open pollinated breeding system, levels of investment, challenges in exploiting hybrid vigour, and yield measured as a repeated harvest of herbage; rather than as seed at maturity in crops such as rice and wheat. Furthermore, the DM yield gains documented in small plots may not translate into increased production or profit at the paddock or farm level (Crush et al. 2006).

These challenges are considered in a recent overview of forage plant breeding which calls for renewed focus on fundamentals including proof of concept, traits per se, balanced investment, and more rigorous experimental design to achieve benefits from forage breeding programmes (Parsons et al. 2010).

Yield is the highest priority trait in most forage plant breeding programmes. It may be increased by capturing heterosis, also called hybrid vigour. Heterosis is the superior performance of progeny arising from crossing genetically divergent parents. The effect is maximised in the first generation and diminishes during subsequent generations of seed increase (McClain 1982). The extent of loss is determined by the reproductive behaviour of the species. While heterosis is achieved if the progeny are superior to the parental average, in practice the hybrid's yield must be superior to the best parent if it is to be of value in agriculture.

The harnessing of hybrid vigour is arguably the greatest practical contribution plant breeding has made to agriculture. It is used in a wide range of economic species including some trees, legumes, small grains, maize, and oilseeds. Established hybrid breeding systems are the result of long term experimentation and investment through stages of development (Stuber 1994). The first stage is assessing if the phenomenon can potentially be expressed at economic levels in a species. It is this stage we begin to address in this paper. The second phase is to characterise patterns of expression using crosses among source populations, and to commercialise partial or fully hybrid cultivars. The third stage addresses the challenge of increasing the levels of yield and hybrid vigour expression between specific elite populations. 
In some species, inbred parents are crossed to make completely hybrid populations. Perennial ryegrass is an obligatory outcrossing species, and severe inbreeding depression precludes development of inbred lines. The most common breeding system in perennial ryegrass develops synthetic populations. The system relies on increase of seed volumes for several generations, resulting in a cultivar which delivers only a portion of the potential hybrid vigour expression on farm (Brummer 1999; McClain 1982).

To increase the portion of hybrid vigour captured, population crosses can be used to produce progeny which are half inter-population hybrids. Brummer (1999) reviewed the status of population hybrids, which he referred to as semi-hybrids, and noted the potential for yield gains in forages. Semi-hybrids in perennial ryegrass have shown yield gains of $4 \%$ up to $20 \%$ in mown swards (Foster 1973; Posselt 1993), but no published data are available on the expression of heterosis under grazing.

Our objective was to explore the first stage of development in a semi-hybrid forage breeding system by assessing, under grazing, the expression of heterosis in perennial ryegrass. This was done using population crosses of existing improved and unimproved populations, including cultivars developed and adapted for grazing in New Zealand. We also aimed to explore seasonality of hybrid vigour expression, and the comparative value of using ecotype or cultivar parental sources.

\section{Methods \\ Plant Material}

Twenty-eight polycrosses were made using all the possible paired combinations among eight parent populations, of which four were cultivars and four were ecotypes. The cultivars were the two early flowering types 'Aries' (A13483) and 'Bronsyn' (A14520), and the two late flowering types, 'Impact' (N1992) and 'Revolution' (A13913). All were infected with AR1 endophyte except 'Impact' which was infected with a wild-type (Standard) endophyte. The four ecotypes were Coruna (A3820), Mangere (A2765), PG1137 (A14946), and Spain*Italy (a bulk of accessions A3585-A3599). Each ecotype was of unknown endophyte status. For each cross, sixteen parents from each population were planted in pots, vernalised, matched for reproductive maturity, and isolated in pollen repellent $(<1.0 \%$ contamination $)$ enclosures, where they pollinated freely. This crossing protocol gives rise to a seed mixture that is expected to be $50 \%$ progeny of inter-population crosses, $25 \%$ progeny of crosses within the one parent population, and $25 \%$ progeny of crosses within the other parent population.
Table 1 Estimated yield of perennial ryegrass semi-hybrid populations, their parents, and check cultivars. Yield was measured for 2 years in small plots managed under sheep grazing on the Manawatu plains.

\begin{tabular}{|c|c|}
\hline Entry & $\begin{array}{l}\text { Dry Matter Yield } \\
\text { (kg/ha/year) }\end{array}$ \\
\hline 'One50' AR1 & 17280 \\
\hline 'Impact' x Coruna & 17070 \\
\hline 'Bronsyn' x 'Revolution' & 17030 \\
\hline 'Bronsyn' x 'Impact' & 16840 \\
\hline 'Revolution' x Spain`Italy & 16740 \\
\hline Mangere $\mathrm{x}$ 'Impact' & 16610 \\
\hline Mangere x 'Revolution' & 16560 \\
\hline 'Extreme' AR1 & 16520 \\
\hline 'Bronsyn' x Coruna & 16500 \\
\hline 'Samson' AR1 & 16480 \\
\hline 'Aries' x 'Impact' & 16,450 \\
\hline 'Impact' AR1 & 16,390 \\
\hline 'Revolution' x 'Impact' & 16,390 \\
\hline PG1137 x 'Aries' & 16,340 \\
\hline 'Aries' x 'Revolution' & 16300 \\
\hline 'Aries' AR1 & 16260 \\
\hline 'Impact' x Spain*Italy & 16240 \\
\hline 'Bronsyn' x Mangere & 16210 \\
\hline 'Aries' x 'Bronsyn' & 16190 \\
\hline 'Bronsyn' AR1 & 15920 \\
\hline 'Revolution' AR1 & 15870 \\
\hline Mangere $\mathrm{x}$ Coruna & 15800 \\
\hline 'Bronsyn' x Spain*Italy & 15790 \\
\hline 'Bronsyn' x PG1137 & 15640 \\
\hline 'Revolution' x Coruna & 15620 \\
\hline 'Impact' x PG1137 & 15610 \\
\hline 'Aries' x Mangere & 15570 \\
\hline Coruna x Spain*Italy & 15500 \\
\hline 'Revolution' x PG1137 & 15220 \\
\hline PG1137 x Spain*Italy & 15090 \\
\hline 'Aries' x Coruna & 15040 \\
\hline Coruna x PG1137 & 14910 \\
\hline 'Aries' x Spain*Italy & 14830 \\
\hline Mangere $x$ Spain*Italy & 14180 \\
\hline Mangere x PG1137 & 14140 \\
\hline PG1137 & 13640 \\
\hline $\operatorname{LSD}_{(0.05)}$ & 1109 \\
\hline
\end{tabular}


Seed were harvested from each plant after flowering was finished, and 28 balanced bulks were constituted and sown in a field trial. Samples of perennial ryegrass cultivars 'Samson', 'One50', and 'Extreme' infected with AR1 endophyte were included in the trial as controls. Samples of each parental population were also included, with the exception of Coruna for which there was insufficient seed.

\section{Experimental design}

A small plot field trial was established in April 2008, at AgResearch's Aorangi Research farm in the Manawatu plains (40 34'S, 175 46'E) in a level paddock of Kairanga fine sandy loam soil. Existing pasture was killed with $540 \mathrm{~g} / \mathrm{L}$ glyphosate with $0.1 \%$ by volume Pulse ${ }^{\circledR}$ surfactant, applied at $4 \mathrm{~L} / \mathrm{ha}$. Following ploughing, fertiliser (N, P, K, S at 15.1:10:10:7.7 ratio) was applied at $250 \mathrm{~kg} / \mathrm{ha}$, and the field power-harrowed to form a fine seedbed. Plots were arranged in a randomised block design with the 38 entries replicated three times, and each plot measuring $6 \mathrm{~m}^{2}$. Plots were hand-sown at a rate of $20 \mathrm{~kg} \mathrm{seed} / \mathrm{ha}$, then raked and rolled to ensure good soil/seed contact.

The trial was visually scored for establishment in June 2008, 8 weeks after sowing. Once established, rotational grazing was commenced at estimated pasture covers of 1400 to $2100 \mathrm{~kg} \mathrm{DM} / \mathrm{ha}$. Herbage accumulation was estimated before each grazing using a grass sward calibrated Pasture Probe ${ }^{\mathrm{TM}}$, collecting 10 data points per plot. Plots were heavily and quickly grazed by sheep after each measurement, and mown to a residual of approximately $1000 \mathrm{~kg} \mathrm{DM} / \mathrm{ha}$. Herbage accumulation data were collected on 19 measurement dates over the 24 month trial.
The trial was kept free of leguminous forages, broadleaf weeds and annual grasses by applying selective herbicides as required. Nitrogen $(\mathrm{N})$ was applied as calcium ammonium nitrate at an elemental $\mathrm{N}$ rate of $3 \%$ of accumulated herbage DM. Applications of $\mathrm{N}$ were made after each grazing, except when there was low rainfall.

Establishment and DM yield data were analysed using the ANOVA as implemented in Genstat statistical analysis software. Hybrid vigour levels were calculated as high parent heterosis, the percent change in yield of the semi-hybrid population relative to the yield of the better parent, as measured in the current experiment.

\section{Results}

All entries, except Mangere and Spain*Italy parent population samples, established successfully. Trial mean DM yield was 14.3 tonnes in the first year and 17.5 tonnes in the second. Analysis of variance revealed significant $(\mathrm{P}<0.05)$ entry effects for $\mathrm{DM}$ yield, with annualised yields ranging from 13.6 to $17.3 \mathrm{t} \mathrm{DM} / \mathrm{ha}$ (Table 1). The ecotype $\mathrm{x}$ ecotype and cultivar $\mathrm{x}$ ecotype progeny either did not perform as well as cultivar $\mathrm{x}$ cultivar progeny or were limited by insufficient viable parental or progeny seed to assess expression of hybrid vigour, and are not considered further.

Cumulative yield among the parental sources and semi-hybrid progeny of cultivar $\mathrm{x}$ cultivar crosses indicated a generally non-significant $(\mathrm{P}>0.05)$ and low level of high parent heterosis, with an average $1.6 \%$ improvement over the better parent's DM yield potential. Each combination exhibited a different level of hybrid vigour expression. The combination 'Bronsyn' $\mathrm{x}$ 'Aries' showed the lowest level of expression with

Table 2 Estimated high parent heterosis by season among six semi-hybrid combinations developed by making pairwise population crosses among four perennial ryegrass cultivars. Yield estimates were made over 2 years under rotational grazing in a small plot replicated field trial in the Manawatu. Values are relative yield of the semi-hybrid combination over 2 years as compared to the higher yielding parent.

\begin{tabular}{|c|c|c|c|c|c|c|c|}
\hline \multicolumn{5}{|c|}{ Winter } & \multicolumn{3}{|c|}{ Spring } \\
\hline 'Revolution' & 110.9 & & & 'Revolution' & 102.7 & & \\
\hline 'Impact' & 104.0 & 106.8 & & 'Impact' & 119.3 & 100.8 & \\
\hline \multirow[t]{3}{*}{ 'Aries' } & 102.1 & 102.2 & 103.9 & 'Aries' & 105.1 & 95.2 & 106.6 \\
\hline & 'Bronsyn' & 'Revolution' & 'Impact' & & 'Bronsyn' & 'Revolution' & 'Impact' \\
\hline & & Summer & & & & Autumn & \\
\hline 'Revolution' & 109.4 & & & 'Revolution' & 106.6 & & \\
\hline 'Impact' & 96.3 & 95.9 & & 'Impact' & 87.8 & 97.4 & \\
\hline \multirow[t]{2}{*}{ 'Aries' } & 95.0 & 106.2 & 94.4 & 'Aries' & 94.7 & 97.8 & 96.3 \\
\hline & 'Bronsyn' & 'Revolution' & 'Impact' & & 'Bronsyn' & 'Revolution' & 'Impact' \\
\hline
\end{tabular}


a $0.5 \%$ decrease in yield compared to the best parent. The combination 'Bronsyn' $\mathrm{x}$ 'Revolution' showed the highest level of expression, a significant $(\mathrm{P}<0.05)$ cumulative DM yield increase of $7.0 \%$ above the better parent over the 2 year trial.

When the DM yield data for cultivar $\mathrm{x}$ cultivar crosses were grouped by season, the analysis revealed seasonal trends in hybrid vigour expression (Table 2). On average, cultivar $\mathrm{x}$ cultivar semi-hybrids expressed $5 \%$ high parent heterosis in both winter and spring; while summer and autumn expression was reduced to 0 and $-3 \%$, respectively. Despite the low average performance of semi-hybrid combinations in summer and autumn, the best semi-hybrids exhibited $9 \%$ and $7 \%$ DM yield advantage over the better parent in summer and autumn, respectively. The best yielding semi-hybrid in winter was $11 \%$ percent higher than its better parent, and in spring the yield of the best semihybrid was $19 \%$ higher than its better parent.

Both the seasonal and the cumulative cultivar $\mathrm{x}$ cultivar data indicated that crosses between early and late types have higher levels of hybrid vigour than crosses between early types or between late types.

\section{Discussion}

This study explores the potential to better harness hybrid vigour in perennial forage breeding systems. Our data suggest that some semi-hybrid combinations in perennial ryegrass have improved cumulative yield relative to the better parent, when assessed in small plots under grazing, and that there are seasonal patterns in the expression of heterosis.

The generally low levels of high parent heterosis in crosses between most sources, with only a few semihybrids exhibiting hybrid vigour, is consistent with findings in other forage studies (Foster 1973; Moutray \& Frakes 1973; Posselt 1993; Riday \& Brummer 2005).

This study is unique in that it reports expression of hybrid vigour assessed under grazing in a competitive sward. Relative to spaced plants or rows, sward assessments dampen DM yield differences among entries (Foster 1973). While more expensive than spaced plant work, the value of our approach is that it is likely to provide results most similar to those observed on farms, as there is sometimes re-ranking of performance in swards relative to rankings observed in spaced plants or rows (Smith et al. 2001; Waldron et al. 2008).

The best semi-hybrid combinations matched but did not exceed the top entry in this study, an elite cultivar which was not used as a parent. On the basis of genetic theory of heterosis (Stuber 1994) it is expected that if new combinations were made with this cultivar, a semihybrid superior to it could be developed.
This experiment did not quantify the proportion of inter and intra-population progeny in the semi-hybrid trial entries, and it is assumed that $50 \%$ of the seed sown, established, and persisting in semi-hybrid plots were from inter-population crosses. DNA marker fingerprints may be used to test these assumptions costeffectively in combinations where initial evaluations show a yield advantage for the semi-hybrid over the better parent.

In cases where hybrid vigour is expressed, there may be scope to increase yield potential through increased hybridity. This has recently been shown in red clover (Trifolium pratense) where $75 \%$ hybridity was achieved through the use of a restricted set of self-incompatibility alleles (Riday \& Krohn 2010). A similar system has been proposed for perennial ryegrass (England 1974), and has been demonstrated (Posselt 1993). It is also possible to use induced sterility to make fully hybrid populations, if the additional cost of breeding and seed production is justified by an increase in heterosis for DM yield potential.

Another unknown in the current experiment is the possibility that the yield changes observed for semi-hybrids were partially or wholly conferred by complementary aspects in the blended seed mixture of the intra-population progeny sown in the semi-hybrid plots, rather than heterosis of the inter-population progeny per se. Despite their widespread availability, there is little published work on cultivar mixture effects on cumulative DM yield in forage grasses. A two cultivar perennial ryegrass mixture had increased DM yield under high fertility and frequent cutting in a controlled experiment, an effect which was attributed to improved light interception (Rhodes 1969). However, when mixtures and pure stands of winter-active and summer-active tall fescue (Festuca arundinacea) were evaluated under grazing, the mixture DM yield of tall fescue was equivalent to the pure stands on an annual basis (Reed et al. 2004). Experiments comparing DM yield potential of perennial ryegrass parent seed mixtures, semi-hybrids, and progeny of semi-hybrids under grazing are needed to confirm to what extent the effects we report are attributed to heterosis versus complementary growth.

Seasonality of yield is a major challenge for pasture plant breeders and the pastoral sector. While cumulative yield is important, stock carrying capacity is limited by the seasonal troughs. In this study, marked seasonal patterns of hybrid vigour expression were observed, with up to $11 \%$ and $19 \%$ improvement compared to the better parent in winter and spring, respectively. While the best yielding combination was different in three of the four seasons, plant breeders may be able to identify or develop combinations which are 
consistently superior across seasons. There is also the need to quantify the level of genotype $\mathrm{x}$ site interaction for expression of hybrid vigour, as these trials were limited to the Manawatu.

Use of a semi-hybrid breeding system will affect seed production and certification, influence plant variety rights in practice, and may influence any self-seeding of pasture after sowing. The production of a semi-hybrid as first generation certified seed could be achieved by sowing a mixture of basic seed of two cultivars. However, most certified ryegrass seed in New Zealand is produced under the OECD Seed Certification Scheme and as an international scheme it could not accept semihybrid production without agreement from international participants to the Scheme. An alternative is the New Zealand Seed Certification Scheme that can be used for seed sold in New Zealand, and in the near term is more likely than the OECD framework to be able to accommodate semi-hybrid seed production.

The agricultural value of many plant species has been improved by making the transition from population or line breeding systems to hybrid breeding systems. It is expected that if the value and levels of hybrid vigour potential are proven, substantial, and amenable to increase in perennial forage species, they too will be available to the pastoral sector as partial or full hybrids offering improved seasonal and cumulative yield potential.

The experiment reported is the initial phase of a possible transition from open pollinated to hybrid breeding systems, and the finding warrants further investigation of semi-hybrid breeding systems for perennial forages to deliver the potential for sustained productivity gains on farm.

\section{ACKNOWLEDGEMENTS}

This work is supported by the Pastoral 21 Feeds programme which includes investment from DairyNZ, Fonterra, Beef + Lamb New Zealand and the Foundation for Research Science and Technology under contract C10X0604. The authors acknowledge the assistance and cooperation of Steve Lees, farm manager at Aorangi and Mr. Michael Hickey, senior technician at AgResearch Grasslands. Dr. Alan Stewart of PGG Wrightson Seeds is acknowledged for provision of an experimental ecotype population.

\section{REFERENCES}

Baenziger, P.S.; Russell, W.K.; Graef, G.L.; Campbell, B.T. 2006. Improving lives: 50 years of crop breeding, genetics, and cytology. Crop Science 46: 2230-2244.

Brummer, E.C. 1999. Capturing heterosis in forage crop cultivar development. Crop Science 39: 943-954.

Crush, J.R.; Woodward, S.L.; Eerens, J.P.J.; MacDonald,
K.A. 2006. Growth and milksolids production in pastures of older and more recent ryegrass and white clover cultivars under dairy grazing. New Zealand Journal of Agricultural Research 49: 119-135.

Easton, H.S.; Baird, D.B.; Cameron, N.E.; Kerr, G.A.; Norriss, M.; Stewart, A.V. 2001. Perennial ryegrass cultivars: herbage yield in multi-site plot trials. Proceedings of the New Zealand Grassland Association 63: 183-188.

England, F.J.W. 1974. The use of incompatibility for the production of $\mathrm{F} 1$ hybrids in forage grasses. Heredity 32: 183-188.

Foster, C.A. 1973. Interpopulational and intervarietal F1 hybrids in Lolium perenne: performance in field sward conditions. Journal of Agricultural Science 80: 463-477.

McClain, E.F. 1982. Effects of generation and method of synthesis on performance of orchardgrass cultivars. Crop Science 22: 1129-1133.

Moutray, J.; Frakes, R. 1973. Effects of genetic diversity on heterosis in tall fescue. Crop Science 13: 1-4.

Parsons, A.J.; Edwards, G.R.; Newton, P.C.D.; Chapman, D.F.; Caradus, J.R.; Rasmussen, S.; Rowarth, J.S. 2010. Past lessons and future prospects: plant breeding for cool temperate pastures. pp. 272291. In: Proceedings of the Australasian Dairy Science Symposium. Ed. Edwards, G. R.

Posselt, U.K. 1993. Hybrid production in Lolium perenne based on incompatibility. Euphytica 71: 2933.

Reed, K.F.M.; Clement, S.L.; Feely, W.F.; Clark, B. 2004. Improving tall fescue (Festuca arundinacea) for cool-season vigour. Australian Journal of Agricultural Research 44: 873-881.

Rhodes, I. 1969. The yield, canopy structure and light interception of two ryegrass varieties in mixed culture and monoculture. Grass \& Forage Science 24: 123-127.

Riday, H.; Brummer, E.C. 2005. Heterosis in a broad range of alfalfa germplasm. Crop Science 45: 8-17.

Riday, H.; Krohn, A.L. 2010. Increasing population hybridity by restricting self-incompatibility alleles in red clover populations. Crop Science 50: 853-860.

Smith, K.F.; Tasneem, M.; Kearney, G.A.; Reed, K.F.M.; Leonforte, A. 2001. Evaluation of herbage yield in a forage grass breeding program: Comparison of visual rating versus measurement in single-row plots or swards. Australian Journal of Experimental Agriculture 41: 1161-1166.

Stuber, C.W. 1994. Heterosis in plant breeding. Plant Breeding Reviews 12: 227-251.

Waldron, B.L.; Robins, J.G.; Peel, M.D.; Jensen, K.B. 2008. Predicted efficiency of spaced-plant selection to indirectly improve tall fescue sward yield and 
quality. Crop Science 48: 443-449.

Williams, W.M.; Easton, H.S.; Jones, C.S. 2007. Future options and targets for pasture plant breeding in New Zealand. New Zealand Journal of Agricultural Research 50: 223-248.

Woodfield, D.R.; Caradus, J.R. 1994. Genetic improvement in White Clover representing six decades of plant breeding. Crop Science 34: 12051213.
Woodfield, D.R.; Easton, H.S. 2004. Advances in pasture plant breeding for animal productivity and health. New Zealand Veterinary Journal 52: 300-310. 